doctors to be opposed to assisted suicide and euthanasia, and despite repeated efforts by the pro-euthanasia lobby at BMA conferences, the BMA retains its opposition to assisted suicide and euthanasia.

The answer to suffering in terminal illness situations is not to kill the sufferer, or to aid them in killing themselves, but is in practising good palliative care. We are very fortunate in the UK in having a very good palliative care system, and improving overall standards of palliative care is the right way forward. It is interesting that the Netherlands has historically had very poor palliative care service, and their answer to much terminal suffering has been to kill patients rather than provide palliative care.

Finally it is questionable whether Clare Gerada has the right to use a BJGP article to express her personal view. As a doctor she is not allowed to let her personal views affect how she looks after patients, and it is questionable whether she should be allowed to use her position of authority to publicly express a personal view. I also trust that, in the interests of fairness, that the BJGP will be publishing in due course a viewpoint from an opponent of legalising assisted suicide, in order to give a balanced view.

\section{Christopher Wayte,}

GP, Bath.

E-mail: chrissallywaytelabtinternet.com

\section{REFERENCE}

1. Gerada C. Viewpoint: The case for neutrality on assisted dying - a personal view. Br J Gen Pract 2012; 62(605): 650 .

DOI: 10.3399/bjgp13X662902

Clare Gerada tells us that the collective view of GPs 'should be confined to speaking on those issues where we have an expertise that goes beyond that of the public'. 'It would appear she does not believe 'assisted dying' to be one of these. I would be all in favour of the medical profession standing back from this issue provided 'assisted dying' isn't placed on the shoulders of doctors; as the campaigners want. They cannot be allowed to have it both ways: to insist that doctors should carry out 'assisted dying' but tell them they must stand back as a profession on the question of whether such practices should be legalised. Dr Gerada says that 'Parliament, not the profession, must decide this issue'. Parliament has decided this issue on at least two occasions in recent years: the answer was No. The trouble is that pro-euthanasia campaigners will not accept the will of Parliament.

Helen Herbert,

GP, Chair of RCGP Wales End of Life Care Group, Tanyfron Surgery, 7-9 Market Street, Aberaeron, Ceredigion, SA46 OAS. E-mail: helen.herbertlauwclub.net

\section{REFERENCE}

1. Gerada C. Viewpoint: The case for neutrality on assisted dying - a personal view. Br J Gen Pract 2012; 62(605): 650 .

\section{DOI: 10.3399/bjgp13X662911}

As a retired GP in his 80s land therefore aware that assisted dying may be a practical and personal issue in the not too distant future) I greatly welcome Clare Gerada's personal plea for strong general practice support for the case for neutrality. ${ }^{1}$ For many years I was a practice colleague of Ann McPherson. In spite of her personal suffering for several years from breast and then pancreatic cancer she found the energy to campaign on behalf of patients on many issues, finally, assisted dying. As her daughter Tess and husband Klim have said, her own pleas for personal assistance near the end were frustrated by the continuing failure to tackle this issue.

As a young GP in the 1960s, I remember the misery experienced by some young patients caused by resistance in the medical profession to abortion reform. As Clare Gerada says, this story is being repeated in relation to assisted dying.

\section{Godfrey Fowler,}

Retired GP and Emeritus Professor of General Practice, Oxford University, 13 Squitchey Lane, Oxford, OX2 7LD. E-mail: godfrey.fowlerlaballiol.ox.ac.uk

\section{REFERENCE}

1. Gerada C. Viewpoint: The case for neutrality on assisted dying - a personal view. Br J Gen Pract 2012; 62(605): 650 .

\section{DOI: 10.3399/bjgp13X662920}

Clare Gerada' suggests that medical bodies should take a neutral stance on the issue of assisted dying and should not be publicly opposed to or support any change in legislation that may allow assisted dying for terminally ill, mentally competent adults. At the heart of the case for neutrality is the principle that the decriminalisation of assisted dying should be a matter for society as a whole to decide, using parliamentary processes. No particular group within it should have a disproportionate influence on this decision. On the other hand, individual healthcare professionals, as responsible citizens, are entitled, perhaps obliged, to express their views about the ethical and clinical case for a law allowing assisted dying for the terminally ill.

Two striking cases, one from the UK and one from Italy, were recently described by Paquita De Zulueta and myself, ${ }^{3}$ and illustrate both the differences and similarities in the debate about assisted dying in different countries, and illuminate the different visions of what constitutes the Good Life and what it is to be human. The increasing secularisation of British society has not yet led to the legalisation of voluntary or involuntary euthanasia, despite the greater emphasis on individual autonomy. Conversely, in Italy, where the Church occupies a more influential position, the law enshrines the doctrine of self-determination, but in practice this is hard to implement.

In both cases some kind of legal compromise was reached: in Italy there was an acceptance that an individual's prior wishes are determinative, even though arguably that person no longer exists, and in England a subjective quality of life assessment was made that permitted treatment to be discontinued in the full knowledge that death would follow. Both decisions aimed to reflect a compassionate and holistic view of what it means to be fully human. ${ }^{4,5}$

Francesco Carelli,

Professor, GP, University of Milan and Rome, Italy. E-mail: carfralatin.it

\section{REFERENCES}

1. Gerada C. The case for neutrality on assisted dying - a personal view. Br J Gen Pract 2012; 62(605): 650

2. Jewell D. Our debt to those who are dying. $\mathrm{Br} J$ Gen Pract 2009; 59(568): 809-810.

3. De Zulueta P, Carelli F. Permanent vegetative state: comparing the law and ethics of two tragic cases from Italy and England. London Journal of Primary Care 2009; 2: 2

4. Carelli F. Euthanasia: why a discussion is urgent between GPs. Medicinae Doctors 2006; 9: 10-11. 
5. Carelli F. Persisent vegetative state. Br J Gen Pract 2012; 60(571): 132

DOI: 10.3399/bjgp13X662939

\section{Tools}

For the last decade or two general practice, indeed medicine in general, has been manufacturing 'tools' as if a 21st century industrial revolution was under way Am I alone in my distaste and negative reactions, feeling that in most cases the word 'tool' is now used in a most ignorant and inappropriate way? Most patients know exactly what tools are, and use them to good effect in the real world. (I once used a tendon hammer, before I retired: a valued tool).

Surely there are many more infinitely preferable words in the English language from which to choose, if concepts such as a scheme, plan, protocol, syllabus, or resource is really what is meant, for something intangible but intended to be teachable (if not necessarily memorable).

While ruminating on why these etymological reflections have kept bothering me continually over the years, and as several dictionaries seemed to support me, I turned to the December $B J G P$ to see if it was as ubiquitous as I thought. On the contents page, I read the very first entry: 'page 621: European Antibiotic Awareness Day 2012: TARGET antibiotics through guidance, education, and ... TOOLS' (my capitals).

The last word triggered something in me - this local etymological mishap had now achieved a European, if not global, dimension. I even read the article, and found this four-lettered t-word not only appeared at the end of Table 1 ('tools to use with patients'), but it had even secreted itself in the acronym 'TARGET' as well as in 'toolkit' (fortunately the acronym was suitably and considerately elaborated for those who can't keep up with them).

I looked back at the contents pages: page 661: Writing therapy: a new tool for general practice? ${ }^{2}$ This saw me reaching instinctively for my pen, to share these thoughts with the Editor. (Very therapeutic!).

At this point I read on in the Journal, and was fascinated to find Neville Goodman's 'Familiarity breeds: clichés in article titles'; and barely surprised to find the errant word quoted in his last sentence. ${ }^{3}$ This monosyllabic t-word, although just a word, not a phrase, surely also has all the characteristics of a cliché, by his definition. It not only appears in article titles, but in the very fabric of our current medical literature, and it is time we called a tool a spade, or at least classed it with coalfaces as reprehensible management-speak.

\section{Hugh Dinwoodie,}

\section{East Trinity Road, Edinburgh.}

E-mail: hugh.dinwoodie1abtinternet.com

\section{REFERENCES}

1. Moore M, McNulty C. European Antibiotic Awareness Day 2012: TARGET antibiotics through guidance, education, and tools. $\mathrm{Br} J$ Gen Pract 2012; 62(605): 621-622

2. Mugerwa S, Holden JD. Writing therapy: a new tool for general practice? Br J Gen Pract 2012; 62(605): 661-663.

3. Goodman N. Familiarity breeds: clichés in article titles. Br J Gen Pract 2012; 62(605): 656-657.

DOI: 10.3399/bjgp13X662948

\section{The 2022 GP: our profession, our patients, our future}

The comments made by Clare Gerada and Ben Riley in the November issue of the $B J G P^{1}$ resonate well with my own views.

Together with fellow GPs in Cape Town, South Africa from 1995-2000, we set up a pilot model of delivering primary care under the auspices of the Health Development Institute a community-based research non-governmental organisation (NGO). ${ }^{2}$ This pilot entailed GPs reaching out to the community through participatory workshops involving the community and other professionals lpriests, lawyers, social workers, teachers, clinical psychologists, and sociologists) in an effort to seek a shared definition, and possible intervention, regarding preventable health problems.

\section{The following workshops were held:}

- On domestic violence, identifying the pitfalls in the implementation of legal provisions like magisterial interdict, as well as how powerful denial is among the women to actually admit that they have an abusive partner, and need help.

- A workshop involving many teachers in three communities who were subjects of a teacher depression epidemic in the Western Cape, a consequence of the rapid social change in South Africa in 1994 from apartheid to democratic rule. The workshop was able to identify support systems that teachers could tap into.

- On unwanted babies for which the government had opted for a technical intervention (legalised abortion) as opposed to social interventions like churches setting up and expanding the adoption services to provide for unwanted babies.

- An AIDS/HIV workshop to find out the community perception of the AIDS epidemic, to what extent do communities feel in a state of helplessness, and what support systems could be set up to empower communities to help themselves; to find out to what extent men saw the need for protected sex using condoms, and the cultural constraints from using condoms.

- Concerning diseases of lifestyle, to find out what the community members perceived as the causes of hypertension, diabetes, heart attacks, and obesity, as well as what public health/political interventions could help to reduce the prevalence of these conditions.

What we noticed afterwards was that the attitudes of the community began to shift from being only consumers of health care to instead being participatory and owning the fight against the community burden of these conditions.

\section{EM Mankazana,}

Freelance GP.

E-mail: mxomankladoctors.net.uk

\section{REFERENCES}

1. Gerada C, Riley B. The 2022 GP: our profession, our patients, our future. Br J Gen Pract 2012; 62(604): $566-567$

2. Mankazana EM. From exile to exile. Autobiography of a South African Black professional in South Africa before, during and after apartheid. New York: Authorhouse, 2011.

\section{Making health habitual}

I was delighted to find that Gardner's useful article on promoting healthy habits ${ }^{1}$ referred to Kahneman's Nobel prizewinning findings about how people think. 